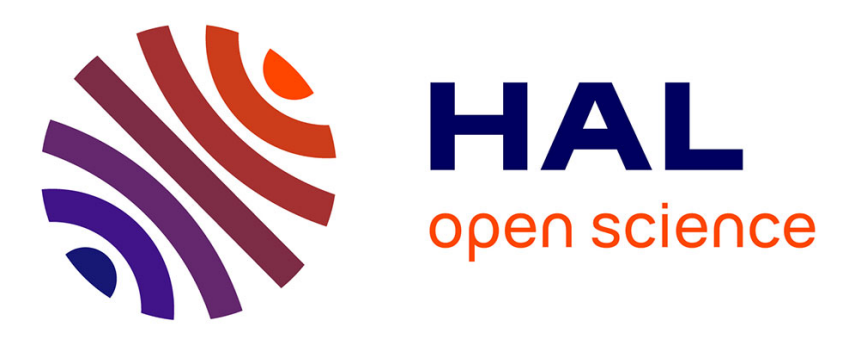

\title{
Model simplification and optimization of a passive wind turbine generator
}

\author{
Bruno Sareni, Abdenour Abdelli, Xavier Roboam, Duc-Hoan Tran
}

\section{To cite this version:}

Bruno Sareni, Abdenour Abdelli, Xavier Roboam, Duc-Hoan Tran. Model simplification and optimization of a passive wind turbine generator. Renewable Energy, 2009, vol. 34, pp.2640-2650. 10.1016/j.renene.2009.04.024 . hal-00763133

\section{HAL Id: hal-00763133 https://hal.science/hal-00763133}

Submitted on 10 Dec 2012

HAL is a multi-disciplinary open access archive for the deposit and dissemination of scientific research documents, whether they are published or not. The documents may come from teaching and research institutions in France or abroad, or from public or private research centers.
L'archive ouverte pluridisciplinaire HAL, est destinée au dépôt et à la diffusion de documents scientifiques de niveau recherche, publiés ou non, émanant des établissements d'enseignement et de recherche français ou étrangers, des laboratoires publics ou privés. 


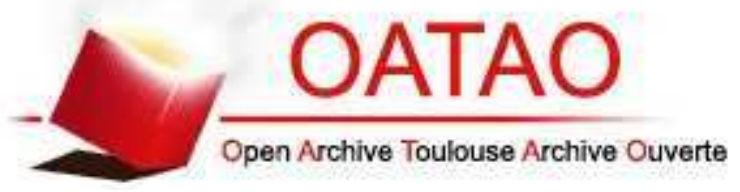

\section{Open Archive TOULOUSE Archive Ouverte (OATAO)}

OATAO is an open access repository that collects the work of Toulouse researchers and makes it freely available over the web where possible.

This is an author-deposited version published in : http://oatao.univ-toulouse.fr/ Eprints ID : 7977

To link to this article : DOI: 10.1016/j.renene.2009.04.024

URL : http://dx.doi.org/10.1016/j.renene.2009.04.024

To cite this version :

Sareni, Bruno and Abdelli, Abdenour and Roboam, Xavier and Tran, Duc-Hoan Model simplification and optimization of a passive wind turbine generator. (2009) Renewable Energy, vol. 34 $\left(\mathrm{n}^{\circ}\right.$ 12). pp. 2640-2650. ISSN 09601481

Any correspondence concerning this service should be sent to the repository administrator: staff-oatao@ listes.diff.inp-toulouse.fr 


\title{
Model simplification and optimization of a passive wind turbine generator
}

\author{
B. Sareni*, A. Abdelli, X. Roboam, D.H. Tran \\ Université de Toulouse, LAPLACE, UMR CNRS-INPT-UPS, Site ENSEEIHT, 2 rue Camichel, 31071 Toulouse Cedex 7, France
}

\begin{abstract}
A B S T R A C T
In this paper, the design of a "low cost full passive structure" of wind turbine system without active electronic part (power and control) is investigated. The efficiency of such device can be obtained only if the design parameters are mutually adapted through an optimization design approach. For this purpose, sizing and simulating models are developed to characterize the behavior and the efficiency of the wind turbine system. A model simplification approach is presented, allowing the reduction of computational times and the investigation of multiple Pareto-optimal solutions with a multiobjective genetic algorithm. Results show that the optimized wind turbine configurations are capable of matching very closely the behavior of active wind turbine systems which operate at optimal wind powers by using a MPPT control device.
\end{abstract}

Wind energy systems

Permanent magnet generator

Multiobjective optimization

Integrated optimal design

Model simplification

\section{Introduction}

Close to high power wind turbines for onshore or offshore applications, small wind systems represent an interesting target for applications such as rural electrification and autonomous energy production networks for water pumping, desalination. Optimizing energy efficiency generally leads to adapt the load impedance and consequently the speed of the generator with the wind turbine operating conditions. Many active structures have been thus proposed [1-15] to allow tracking the maximum power operation through corresponding MPPT strategies.

However, for such application frame, the system cost has to be drastically minimized for instance by simplifying the structure with PM synchronous generator feeding a diode rectifier associated with a battery bus. For grid connected applications, impedance adaptation can be obtained through the grid inverter as in [13]. In this paper we propose a very "low cost structure" for remote applications without active control unit and with a minimum number of sensors. In fact, for such device a "natural" impedance adaptation can be achieved with the passive structure by optimizing the accordance between system parameters [15-18].

The paper is organized as follows. In Section 2, the architecture of the passive wind turbine system considered in this study is described and the mechanical behavior of the turbine is given. In Sections 3 and 4 the sizing models of the wind turbine generator

\footnotetext{
Corresponding author

E-mail address: sareni@laplace.univ-tlse.fr (B. Sareni).
}

and of the diode rectifier are developed, considering multiple viewpoints (geometrical features, thermal and electrical characteristics). Section 5 is dedicated to the models simulating the wind turbine systems. In particular, a model simplification approach is presented in order to obtain reduced models with low computational times and acceptable accuracy. Finally, the multiobjective optimization of passive wind turbine generators is investigated in Section 6. The complete optimization process is developed and the Pareto-optimal configurations obtained for a particular wind cycle are presented and analyzed considering different standpoints (wind extraction, energetic behavior, model sensitivity).

\section{The small passive wind turbine system}

\subsection{The wind turbine structure}

In order to minimize the system cost and to maximize its reliability, the "full passive" architecture of Fig. 1 is put forward. This structure is mainly dedicated to small scale wind turbines, particularly for remote systems. A battery bank is then associated to a passive diode rectifier to allow an autonomous system operation. A minimum number of sensors and no control unit is required in this "low cost" structure.

The main drawback of this structure is its poor energetic efficiency. However, it will be shown in the following sections, that it can be clearly improved if some design parameters are properly chosen, through an integrated optimal design approach similar to that presented in $[17,19,26]$. 


\begin{tabular}{|c|c|c|c|}
\hline \multicolumn{2}{|c|}{ Nomenclature } & $V_{\mathrm{b}}$ & base voltage \\
\hline \multicolumn{2}{|c|}{ Wind turbine variables } & $\omega$ & electrical pulsation \\
\hline$C_{\mathrm{p}}$ & wind turbine power coefficient & $T_{\mathrm{em}}$ & electromagnetic torque \\
\hline & wind turbine rotational speed & $J_{\mathrm{s}}$ & current density \\
\hline & wind turbine torque & $B_{\mathrm{y}}$ & yoke induction \\
\hline$\lambda$ & tip speed ratio & $B_{1 \mathrm{~g}}$ & airgap induction \\
\hline$A$ & swept rotor area & $\alpha_{\mathrm{m}}$ & electrical half pole width \\
\hline JWT & wind turbine inertia & $K_{\mathrm{c}}$ & Carter coefficient \\
\hline$T_{\mathrm{WT}}$ & wind turbine damping coefficient & $\mu_{\mathrm{r}}$ & magnet permeability \\
\hline & wind speed & $\begin{array}{l}B_{\mathrm{r}} \\
L_{\mathrm{l}}\end{array}$ & $\begin{array}{l}\text { magnet remanent induction } \\
\text { leakage inductance }\end{array}$ \\
\hline \multicolumn{2}{|c|}{ PMSG geometric variables } & $L_{\mathrm{m}}$ & main inductance \\
\hline$R_{\mathrm{rl}}$ & radius length ratio & $L_{\mathrm{s}}$ & stator inductance \\
\hline$r_{\mathrm{s}}$ & bore radius & $\Phi_{\mathrm{s}}$ & stator flux \\
\hline$l_{\mathrm{r}}$ & machine length & $R_{\mathrm{S}}$ & stator resistance \\
\hline$p$ & number of pole pairs & $I_{\mathrm{s}}$ & stator current \\
\hline$g$ & air gap & $V_{\mathrm{s}}$ & stator voltage \\
\hline$l_{\mathrm{m}}$ & magnet thickness & $P_{\mathrm{J}}$ & Joule loss \\
\hline & magnet width & $P_{\text {Eddy }}$ & eddy current loss \\
\hline & slot width & $P_{\text {Hyst }}$ & hysteresis loss \\
\hline & slot depth & & \\
\hline & teeth width & \multicolumn{2}{|c|}{ PMSG thermal variables } \\
\hline$d_{\mathrm{y}}$ & yoke thickness & $r_{i}$ & equivalent radius of a component $i$ \\
\hline$R_{\mathrm{dr}}$ & slot depth bore radius ratio & $R_{i}$ & thermal resistance of a component $i$ \\
\hline$N_{\mathrm{spp}}$ & number of slots per pole per phase & $C_{i}$ & thermal capacity of a component $i$ \\
\hline & number of conductors per slot & $\lambda_{i}$ & thermal conductivity of a component $i$ \\
\hline & slot filling coefficient & $h_{i}$ & heat transfer coefficient of a component $i$ \\
\hline & winding factor & $T_{i}$ & temperature of a component $i$ \\
\hline & volume of an element $i$ & & \\
\hline$M_{i}$ & mass of an element $i$ & \multicolumn{2}{|c|}{ Diode rectifier variables } \\
\hline \multirow[t]{2}{*}{$\rho_{i}$} & mass density of an element $i$ & $R_{\mathrm{d}}$ & diode resistance \\
\hline & & & diode voltage drop \\
\hline \multicolumn{2}{|c|}{ PMSG electromagnetic and electromechanical variables } & & diode current \\
\hline & base speed & $P_{\text {cond }}$ & conduction loss \\
\hline$T_{\mathrm{b}}$ & base torque & $R_{\mathrm{TH} \_\mathrm{RAD}}$ & radiator thermal resistance \\
\hline$P_{\mathrm{b}}$ & base power & $M_{\mathrm{rad}}$ & radiator mass \\
\hline
\end{tabular}

\subsection{The wind turbine model}

A Savonius vertical axis wind turbine of radius $R=0.5 \mathrm{~m}$ and height $H=2 \mathrm{~m}$ is considered as case study (see Fig. 2).

It has to be noticed that the proposed structure and the corresponding design process could be applied for any vertical or horizontal axis turbines. However, due to its bell shape power coefficient $\left(C_{\mathrm{p}}(\lambda)\right)$, the Savonius turbine requires to conveniently adapt the shaft speed with respect to wind levels. Thus, it is

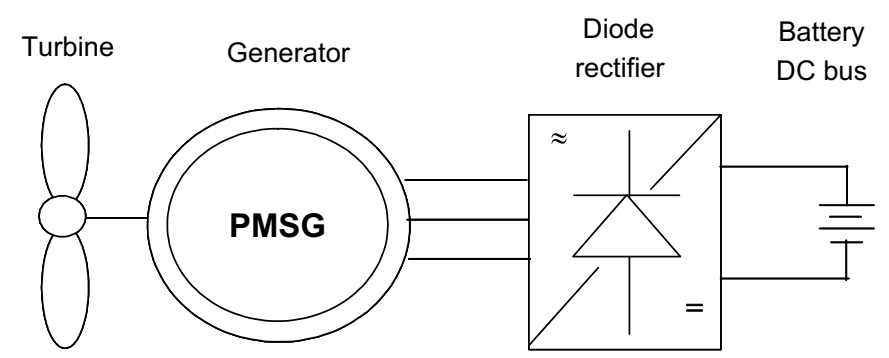

Fig. 1. The "full passive" structure of the wind turbine system. certainly a good application to present the efficiency of the optimization based design of the passive structure. In this particular case study, the power coefficient $\left(C_{p}\right)$ is defined by the following empirical relation:

$C_{\mathrm{p}}=-0.1299 \lambda^{3}-0.1168 \lambda^{2}+0.4540 \lambda$

where $\lambda$ is the tip speed ratio, depending on the turbine rotational speed $\Omega$ and the wind speed $V_{\mathrm{W}}$.

$$
\lambda=\frac{R \Omega}{V_{\mathrm{W}}}
$$

The associated wind turbine power is defined as [20]:

$P_{\mathrm{WT}}=\frac{1}{2} C_{\mathrm{p}} \rho A V_{\mathrm{W}}^{3}$

where $\rho$ denotes the air density $\left(\rho \sim 1.2 \mathrm{~kg} \mathrm{~m}^{-3}\right)$ and $A$ represents the swept rotor area. It is noticed that the wind power is maximum when the power coefficient is maximum $\left(C_{\mathrm{p}}{ }^{*} \approx 0.22\right)$, i.e. for the optimal tip speed ratio $\left(\lambda^{*} \approx 0.82\right)$. For various wind speed values, the rotor speed should be adapted to operate close to the optimal tip speed ratio. 


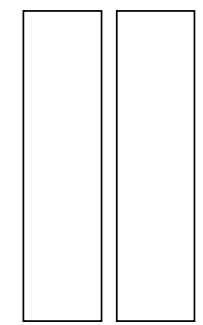

$A \approx 2 R \cdot H$

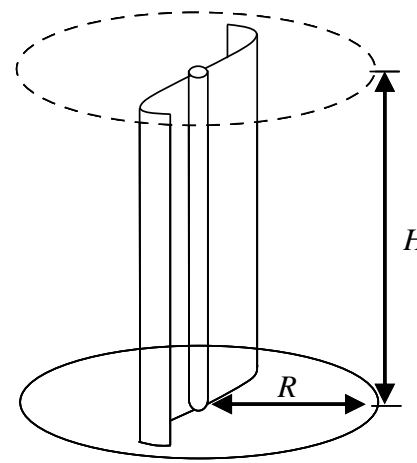

Fig. 2. The Savonius wind turbine with its corresponding power coefficient

The corresponding wind turbine torque $T_{\mathrm{WT}}$ can thus be expressed:

$T_{\mathrm{WT}}=a \Omega^{2}+b \Omega+c$

where

$\left\{\begin{array}{l}a=-\frac{1}{2} \rho A \times 0.130 R^{3} \\ b=\frac{1}{2} \rho A \times 0.117 R^{2} V_{\mathrm{W}} \Omega \\ c=\frac{1}{2} \rho A \times 0.454 R V_{\mathrm{W}}^{2}\end{array}\right.$

The dynamic model of the turbine can be represented by:

$T_{\mathrm{em}}=T_{\mathrm{WT}}-J_{\mathrm{WT}} \frac{\mathrm{d} \Omega}{\mathrm{d} t}-F_{\mathrm{WT}} \Omega$

where the wind turbine inertia and the damping coefficient are, respectively, $J_{\mathrm{WT}}=16 \mathrm{~kg} \mathrm{~m}^{2}$ and $F_{\mathrm{WT}}=0.06 \mathrm{Nms} / \mathrm{rad} \Omega$ is the mechanical shaft speed and $T_{\mathrm{em}}$ denotes the electromagnetic torque of the generator.

\section{The sizing model of the permanent magnet synchronous generator}

The sizing model of the permanent magnet synchronous generator (PMSG) has been developed in [19,21]. It depends on geometrical characteristics (number of pole pairs $p$, number of slots per pole per phase $N_{\mathrm{spp}}$, radius/length ratio $R_{\mathrm{rl}}=r_{\mathrm{s}} / l_{\mathrm{r}}$ ) as well as electromechanical features (current density $J_{\mathrm{s}}$, yoke induction $\widehat{B}_{\mathrm{y}}$, base speed $\Omega_{\mathrm{b}}$ and corresponding power at the base point $P_{\mathrm{b}}$ ).

\subsection{The PMSG geometric model}

\subsubsection{Calculation of geometrical characteristics}

The geometrical characteristics of the generator are shown in Fig. 3.

The bore radius $r_{\mathrm{s}}$ is related to the fundamental value of the air gap magnetic flux density $\left(B_{1 \mathrm{~g}}\right)$ and the slot depth/bore radius ratio $R_{\mathrm{dr}}\left(R_{\mathrm{dr}}=d_{\mathrm{s}} / r_{\mathrm{s}}\right)$ as follows:

$r_{\mathrm{s}}=\left(T_{\mathrm{b}} R_{\mathrm{rl}} \frac{1}{J_{\mathrm{S}} K_{\mathrm{r}} B_{1 \mathrm{~g}} R_{\mathrm{d} r} \pi}\right)^{\frac{1}{4}}$

where $K_{\mathrm{r}}$ is the slot filling coefficient. $B_{1 \mathrm{~g}}$ is computed from the magnet properties (relative permeability $\mu_{\mathrm{r}}=1.05$ and remanent induction $B_{\mathrm{r}}=1.1 \mathrm{~T}$ for NdFeB magnet) and from the electrical half pole width $\alpha_{\mathrm{m}}$ :

$B_{1 \mathrm{~g}}=\frac{4}{\pi} B_{r} \frac{l_{\mathrm{m}} / g^{\prime}}{\mu_{r}+\left(l_{\mathrm{m}} / g^{\prime}\right)} \sin \left(\alpha_{\mathrm{m}}\right)$

where $l_{\mathrm{m}} / g^{\prime}$ represents the ratio between the magnet thickness and the air gap corrected by the carter coefficient. In these two equations, the unknown variables are set to typical values, i.e. $R_{\mathrm{dr}}=0.25$, $K_{\mathrm{r}}=0.5, \alpha_{\mathrm{m}} \approx 1.31$ (i.e. $75^{\circ}$ ) and $l_{\mathrm{m}} / g^{\prime}=3.5$ while the Carter coefficient is set to 1.05 .

The magnet width $w_{\mathrm{m}}$ can be deduced from:

$w_{\mathrm{m}}=\frac{r_{\mathrm{s}} \alpha_{\mathrm{m}}}{p}$

The generator air gap $g$ is calculated from the empirical relation:

$g=0.001+0.003 r_{\mathrm{s}} / \sqrt{R_{\mathrm{rl}}}$ a

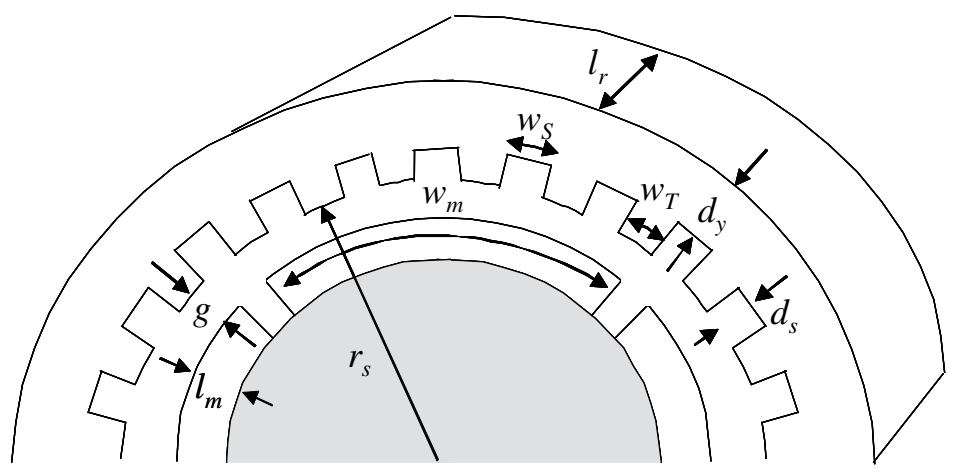

Global geometry

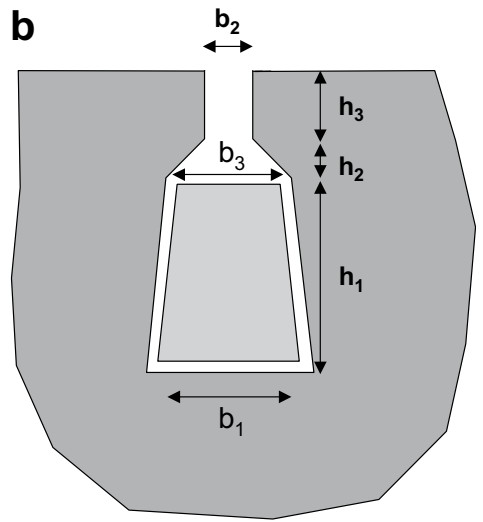

Slot characteristics

Fig. 3. The geometrical characteristics of the PMSG 
Tooth and slot widths are then obtained from the bore radius and the number of slots per pole per phase $N_{\mathrm{spp}}$ :

$w_{\mathrm{S}}=w_{\mathrm{T}}=\frac{\pi r_{\mathrm{s}}}{6 p N_{\mathrm{spp}}}$

and the slot depth $d_{\mathrm{S}}$ is given by:

$d_{\mathrm{S}}=R_{\mathrm{dr}} r_{\mathrm{S}}$

Finally, the yoke thickness is obtained as follows:

$d_{\mathrm{y}}=\frac{r_{\mathrm{s}}}{p} \alpha_{\mathrm{m}} \frac{\widehat{B}_{\mathrm{g}}}{\widehat{B}_{\mathrm{y}}}$

where the maximum magnetic flux density in the air gap is evaluated from the following relation:

$\widehat{B}_{\mathrm{g}}=B_{\mathrm{r}} \frac{l_{\mathrm{m}} / g^{\prime}}{\mu_{\mathrm{r}}+l_{\mathrm{m}} / g^{\prime}}$

\subsubsection{Calculation of generator volumes and masses}

The generator masses are obtained from the volume of each constitutive element and from the corresponding mass density. The rotor volume $V_{\text {rotor }}$ can be approximated as:

$V_{\text {rotor }}=\pi l_{\mathrm{r}}\left(r_{\text {rotor }}^{2}-\left(r_{\text {rotor }}-d_{\mathrm{y}}\right)^{2}\right)$

where $r_{\text {rotor }}=r_{\mathrm{s}}-g-l_{\mathrm{m}}$ and $d_{\mathrm{R}}=d_{\mathrm{y}}$. The corresponding mass is given by:

$M_{\text {rotor }}=V_{\text {rotor }} \rho_{\text {iron }}$

The stator volume $V_{\text {stator }}$ is composed of yoke and teeth volumes

$V_{\text {stator }}=V_{\text {teeth }}+V_{\text {yoke }}$

which can be approximated as follows:

$\left\{\begin{array}{l}V_{\text {yoke }}=2 \pi l_{\mathrm{r}} d_{\mathrm{y}}\left(r_{\mathrm{s}}+d_{\mathrm{S}}+d_{\mathrm{y}} / 2\right) \\ V_{\text {teeth }}=\pi l_{\mathrm{r}} d_{\mathrm{S}}\left(r_{\mathrm{s}}+d_{\mathrm{S}} / 2\right)\end{array}\right.$

The corresponding mass is

$M_{\text {stator }}=V_{\text {stator }} \rho_{\text {iron }}$

The total iron mass in the generator can be expressed by summing stator and rotor iron masses

$M_{\text {iron }}=M_{\text {stator }}+M_{\text {rotor }}$

Similarly, the magnet volume is given by:

$V_{\text {magnet }}=2 \alpha_{\mathrm{m}} l_{\mathrm{r}}\left(\left(r_{\mathrm{s}}-g\right)^{2}-r_{\text {rotor }}^{2}\right)$

and the corresponding mass by:

$M_{\text {magnet }}=\rho_{\text {magnet }} V_{\text {magnet }}$

with $\rho_{\text {magnet }}=7400 \mathrm{~kg} \mathrm{~m}^{-3}$.

Finally, the copper mass is deduced from the copper volumes in the slots and in the winding heads

$\left\{\begin{array}{l}V_{\text {copper }}^{\text {slot }}=\pi l_{\mathrm{r}} K_{\mathrm{r}} d_{\mathrm{S}}\left(r_{\mathrm{S}}+d_{\mathrm{S}} / 2\right) \\ V_{\text {copper }}^{\text {head }}=6 \pi\left(r_{\mathrm{s}}+d_{\mathrm{S}} / 2\right) d_{\mathrm{S}} w_{\mathrm{S}} K_{\mathrm{r}} N_{\mathrm{spp}}\end{array}\right.$

which implies

$M_{\text {copper }}=\rho_{\text {copper }}\left(V_{\text {copper }}^{\text {head }}+V_{\text {copper }}^{\text {slot }}\right)$
The total mass of the generator is then approximated by summing the masses related to each component:

$M_{\text {motor }}=M_{\text {iron }}+M_{\text {copper }}+M_{\text {magnet }}$

\subsection{The PMSG electric model}

3.2.1. Calculation of the electromagnetic parameters

Electromagnetic parameters of the generator are computed from the previous geometric variables. In particular, leakage inductances $L_{1}$ are obtained from [22] by considering a trapezoidal slot as shown in Fig. 3

$L_{1}=2 \mu_{0} l_{\mathrm{r}} p N_{\mathrm{spp}} \lambda_{\mathrm{s}} N_{\mathrm{cs}}^{2}$

where $N_{\mathrm{cs}}$ denotes the number of conductors per slot and where the $\lambda_{s}$ coefficient depends on the slot geometrical characteristics (27) and (28).

$\lambda_{\mathrm{S}}=\frac{2 h_{1}}{3\left(b_{1}+b_{3}\right)}+\frac{2 h_{2}}{b_{2}+b_{3}}+\frac{h_{3}}{b_{2}}$

with

$\left\{\begin{array}{l}h_{1}=8 d_{\mathrm{S}} K_{\mathrm{r}} / 7 \\ h_{2}=w_{\mathrm{S}} / 8 \\ h_{3}=0.02 r_{\mathrm{s}} \\ b_{1}=w_{\mathrm{S}} \\ b_{2}=w_{\mathrm{S}} / 2 \\ b_{3}=3 w_{\mathrm{S}} / 4\end{array}\right.$

The main inductance $L_{\mathrm{m}}$ can be expressed as:

$L_{\mathrm{m}}=\frac{4 \mu_{0} r_{\mathrm{s}} l_{\mathrm{r}}}{\pi\left(K_{\mathrm{c}} g+l_{\mathrm{m}} / \mu_{\mathrm{r}}\right)} N_{\mathrm{spp}}^{2} K_{1 \mathrm{~b}}^{2} N_{\mathrm{cs}}^{2}$

where the winding factor $K_{1}$ is given by the following relation:

$K_{1 \mathrm{~b}}=\frac{\sin (\pi / 6)}{N_{\mathrm{spp}} \sin \left(\pi / 6 N_{\mathrm{spp}}\right)}$

The corresponding stator inductance $L_{\mathrm{S}}$ is defined as follows:

$L_{\mathrm{s}}=\frac{3}{2} L_{\mathrm{m}}+L_{\mathrm{l}}$

It can be noted that these inductance values can also be computed from the generator geometric features with the Finite Element Method $[17,18]$ for a better accuracy.

The magnetic flux $\Phi_{\mathrm{s}}$ and the stator resistance $R_{\mathrm{S}}$ are defined as follows:

$\Phi_{\mathrm{s}}=2 K_{1 \mathrm{~b}} N_{\mathrm{spp}} B_{1 \mathrm{~g}} r_{\mathrm{s}} l_{\mathrm{r}} N_{\mathrm{cs}}$

$R_{\mathrm{S}}=12 \rho_{\text {copper }}\left[l_{\mathrm{r}}+\frac{\pi\left(r_{\mathrm{s}}+0.5 d_{\mathrm{S}}\right)}{p}\right] \frac{p^{2} N_{\mathrm{spp}}^{2}}{\pi r_{\mathrm{s}} d_{\mathrm{S}} K_{\mathrm{r}}} N_{\mathrm{cs}}^{2}$

Finally, the generator current $I_{\mathrm{S}}$ can be obtained from the current density $J_{s}$ :

$I_{\mathrm{s}}=\frac{J_{\mathrm{s}} d_{\mathrm{s}} K_{\mathrm{r}} \pi r_{\mathrm{s}}}{6 p N_{\mathrm{spp}} N_{\mathrm{cs}}}$

To compute all parameters of the generator, the number of conductors $N_{\mathrm{cs}}$ in one slot has to be determined. It should be designed in order to fulfil the operating conditions at the base point. The permanent magnet machine must be able to provide the base torque $T_{\mathrm{m}}=T_{\mathrm{b}}$ under the supply voltage $V_{\mathrm{m}}=V_{\mathrm{b}}$ at the electrical pulsation $\omega=\omega_{\mathrm{b}}$. By setting $N_{\mathrm{cs}}=1$ in Eqs. (26), (29), (32), (33) 


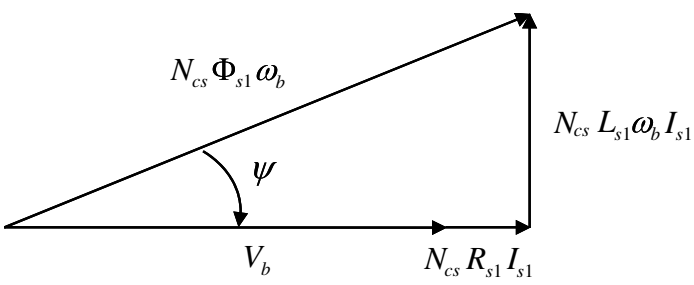

Fig. 4. The electrical diagram of the generator at the base point.

and (34) circuit variables $L_{11}, L_{\mathrm{m} 1}, L_{\mathrm{s} 1}, \Phi_{\mathrm{s} 1} R_{\mathrm{s} 1}$ and $I_{\mathrm{s} 1}$ can be obtained for one conductor per slot:

$\left\{\begin{array}{c}L_{\mathrm{l}}=N_{\mathrm{cs}}^{2} L_{11} \\ L_{\mathrm{m}}=N_{\mathrm{cs}}^{2} L_{\mathrm{m} 1} \\ L_{\mathrm{s}}=N_{\mathrm{cs}}^{2} L_{\mathrm{s} 1} \\ \Phi_{\mathrm{s}}=N_{\mathrm{cs}} \Phi_{\mathrm{s} 1} \\ R_{\mathrm{s}}=N_{\mathrm{cs}}^{2} R_{\mathrm{s} 1} \\ I_{\mathrm{s}}=I_{\mathrm{s} 1} / N_{\mathrm{cs}}\end{array}\right.$

By considering the electrical diagram of the generator (see Fig. 4), operating at the base point $\left(T_{b}, \omega_{b}\right)$, the number of conductors in one slot can be obtained by solving (36):

$$
\begin{aligned}
N_{\mathrm{cs}}^{2}-\frac{2 V_{\mathrm{b}} R_{\mathrm{s} 1} I_{\mathrm{s} 1}}{\left(\Phi_{\mathrm{s} 1} \omega_{\mathrm{b}}\right)^{2}-\left[R_{\mathrm{s} 1}^{2}+\left(L_{\mathrm{s} 1} \omega_{\mathrm{b}}\right)^{2}\right] I_{\mathrm{s} 1}^{2}} N_{\mathrm{cs}} \\
-\frac{V_{\mathrm{b}}^{2}}{\left(\Phi_{\mathrm{s} 1} \omega_{\mathrm{b}}\right)^{2}-\left[R_{\mathrm{s} 1}^{2}+\left(L_{\mathrm{s} 1} \omega_{\mathrm{b}}\right)^{2}\right] I_{\mathrm{s} 1}^{2}}=0
\end{aligned}
$$

Thanks to the calculation of the circuit parameters $\left(R_{\mathrm{S}}, L_{\mathrm{S}}, \Phi_{\mathrm{S}}\right)$, a circuit (a,bc) 3-phase model can be derived. This latter model will be considered as the "reference model" of the generator.

\subsubsection{Calculation of the generator losses}

Iron losses in the generator are divided into hysteresis $\left(P_{\text {Hyst }}\right)$ and eddy current losses $\left(P_{\text {Eddy }}\right)$ in the stator parts (i.e. yoke and teeth). Iron losses in the yoke are computed as follows [23]:

$$
\left\{\begin{array}{l}
P_{\text {Hyst }}^{\text {yoke }}=V_{\text {yoke }} \frac{2 K_{H}}{\pi} \widehat{B}_{y}^{2} \omega \\
P_{\text {Eddy }}^{\text {yoke }}=V_{\text {yoke }} \frac{4 \alpha_{\mathrm{p}}}{\pi^{2} K_{p}} \widehat{B}_{y}^{2} \omega^{2}
\end{array}\right.
$$

where the filling coefficient $K_{p}$ equals 0.833 and $K_{H}$ and $\alpha_{p}$ are empirical factors depending on the material (typically $K_{H}=52$ and $\alpha_{p}=0.06$ for FeSi 3\%). Similarly, iron losses in the teeth can be deduced by the following relation
$\left\{\begin{array}{l}P_{\text {Hyst }}^{\text {teeth }}=V_{\text {teeth }} \frac{2 K_{\mathrm{H}}}{\pi} \widehat{B}_{\text {teeth }}{ }^{2} \omega \\ P_{\text {Eddy }}^{\text {teeth }}=V_{\text {teeth }} \frac{12 \alpha_{\mathrm{p}} N_{\text {spp }}}{\pi^{2}} \widehat{B}_{\text {teeth }}{ }^{2} \omega^{2}\end{array}\right.$

with

$\widehat{B}_{\text {teeth }}=\frac{\widehat{B}_{\mathrm{g}}}{0.5+\left(d_{\mathrm{S}} / 3 r_{\mathrm{s}}\right)}$

Global iron losses in the generator are then obtained by summing all hysteresis and eddy current losses:

$P_{\text {iron }}=P_{\text {Hyst }}^{\text {yoke }}+P_{\text {Eddy }}^{\text {yoke }}+P_{\text {Hyst }}^{\text {teeth }}+P_{\text {Eddy }}^{\text {teeth }}$

Finally, Joule losses $P_{\mathrm{j}}$ can be classically computed as follows:

$P_{\mathrm{j}}=3 R_{\mathrm{s}} I_{\mathrm{s}}^{2}$

\subsection{The PMSG thermal model}

An additional circuit model simulates the thermal behavior of all generator constitutive elements (slot copper, slot insulation, stator yoke) with respect to their thermal characteristics (thermal resistance and capacity of the corresponding elements) and regarding external conditions (i.e. the surrounding temperature). This model is coupled with electromagnetic phenomena through iron and Joule losses (see Fig. 5). The expressions of thermal resistances and capacities are not given in the paper but can be found in [18,19].

\section{The sizing model of the diode rectifier}

A 36MT120 is considered for the diode rectifier. Power losses in the diode rectifier result from conduction losses that can be expressed as:

$$
P_{\text {cond }}=2\left(u_{\mathrm{d}} i_{\mathrm{d}}+R_{\mathrm{d}} i_{\mathrm{d}}^{2}\right)
$$

where $u_{\mathrm{d}}$ is the diode voltage drop and $R_{\mathrm{d}}$ represents the diode internal resistance (typically $R_{\mathrm{d}}=3.4 \mathrm{~m} \Omega$ and $u_{\mathrm{d}}=0.8 \mathrm{~V}$ ). It should be noted that switching losses are neglected. A thermal model of the rectifier based on a classical state-circuit representation allows us to size the thermal resistance of the radiator $R_{\mathrm{TH} \_\mathrm{RAD}}$ in order to operate at nominal conditions (i.e. at the generator base point) below the semiconductor temperature limit (typically $T_{\text {jmax }} 125^{\circ} \mathrm{C}$ or $398 \mathrm{~K}$ ). This model is represented in Fig. 6.

By considering that thermal circuit at steady state, the value of the radiator thermal resistance can be deduced as:

$R_{\mathrm{TH} \_\mathrm{RAD}}=\frac{\Delta T}{P_{\text {cond }}}-\left(R_{\mathrm{TH} 1}+R_{\mathrm{TH} 2}\right)$

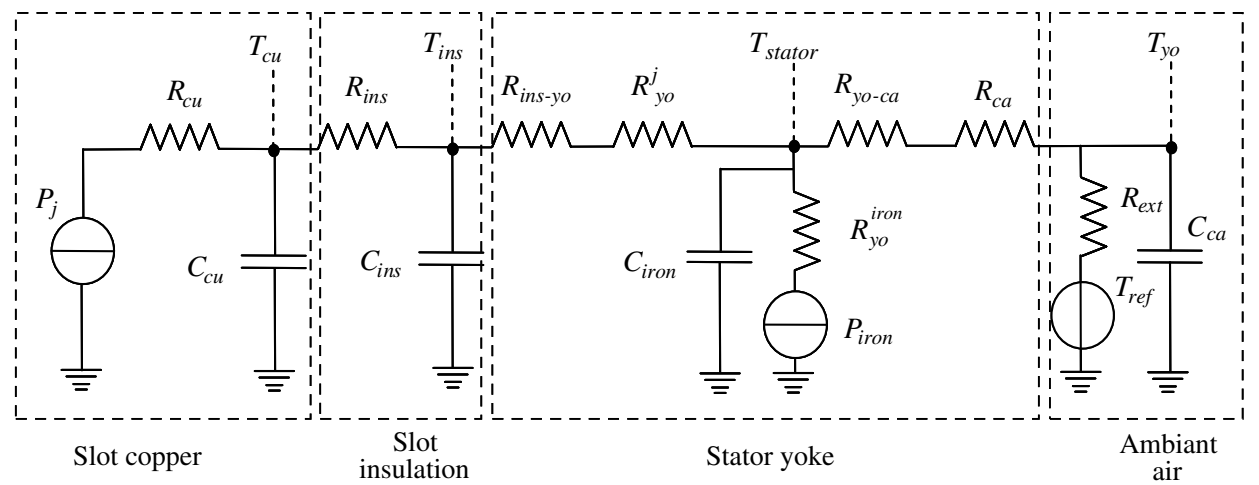

Fig. 5. The thermal model of the generator 


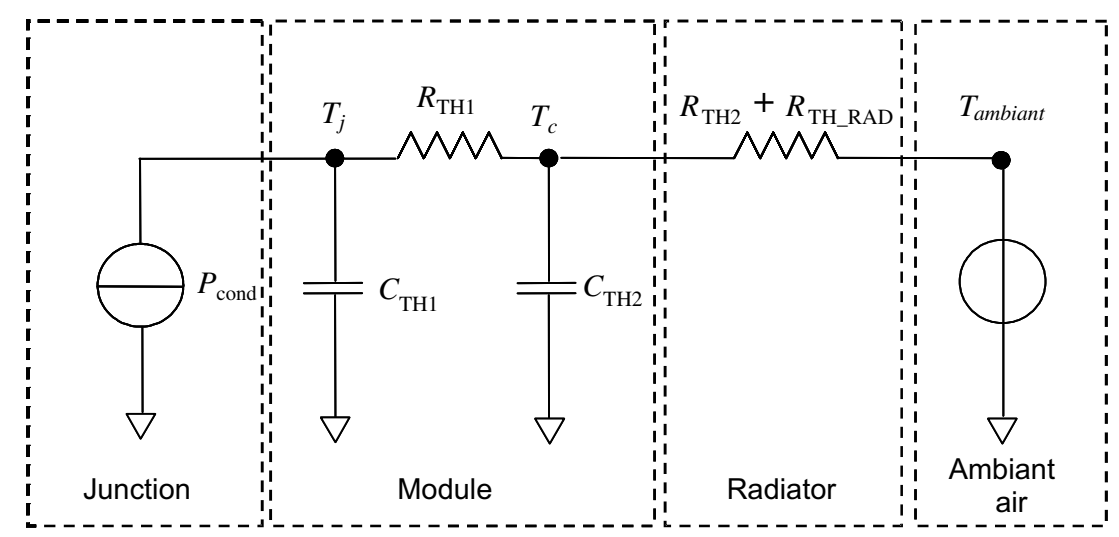

Fig. 6. The thermal model of the diode rectifier.

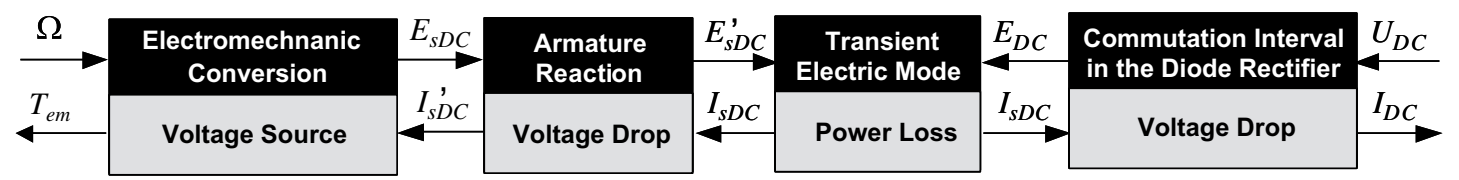

Fig. 7. The causal synoptic of the equivalent DC model.

where $\Delta T=T_{\text {jmax }}-T_{\text {ambiant }}$ (typically $T_{\text {ambiant }}=25^{\circ} \mathrm{C}$, i.e. $298 \mathrm{~K}$ ) and with $R_{\mathrm{TH} 1}=1.35 \mathrm{~K} \mathrm{~W}^{-1}$ and $R_{\mathrm{TH} 2}=0.2 \mathrm{~K} \mathrm{~W}^{-1}$ for the $36 \mathrm{MT} 120$ diode rectifier. Then, the radiator length is obtained from the thermal resistance by interpolating manufacturer's data. We consider three different extrusion profiles of the manufacturer AAVID THERMALLOY for a thermal resistance variation in the range: $0.5 \mathrm{KW}^{-1} \leq R_{\mathrm{TH} \_\mathrm{RAD}} \leq 12 \mathrm{KW}^{-1}$.

Finally, the rectifier mass is approximated by the radiator mass $M_{\text {rad }}$ evaluated from the corresponding length and the mass density per unit length.

\section{Model simplification of the passive wind turbine system}

\subsection{The reference model}

A "reference model" has firstly been proposed in order to validate the temporal system simulation [18]. This model associates a complete (a,b,c) circuit model of the generator with a diode bridge rectifier including ideal switches but taking into account the diode overlapping during switching intervals. Since the computational cost associated with the reference model is really too high important in the framework of system optimization, surrogate models have been developed in order to reduce computational times.

\subsection{The equivalent $D C$ model}

A first simplified causal model has been developed where the synchronous generator with the diode bridge association is replaced with an energetically equivalent DC model valid in average value

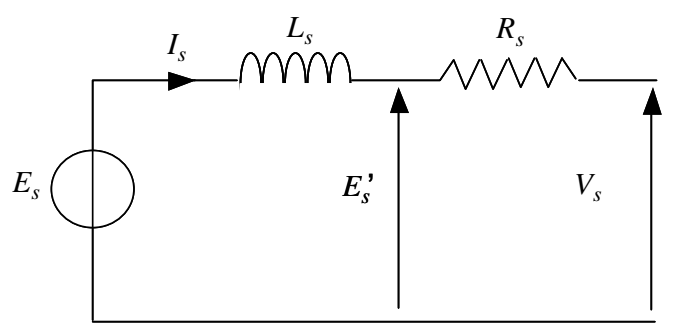

Fig. 8. The synchronous generator equivalent circuit.
$[17,18]$. The synoptic of this model is given in Fig. 7. The causality is symbolized by arrows specifying which physical variables (energetic efforts or flows) are applied to each part of the system. The correspondence between AC (rms) values and DC ones, in the synchronous generator circuit model (see Fig. 8) is given in Table 1.

The electromechanical conversion is represented by:

$$
\left\{\begin{array}{l}
T_{\mathrm{em}}=p \Phi_{\mathrm{DC}} I_{\mathrm{sDC}}^{\prime} \\
E_{\mathrm{SDC}}=p \Phi_{\mathrm{DC}} \Omega
\end{array}\right.
$$

where $p$ is the pole pair number of the generator. The armature reaction in the generator is modelled with a voltage drop without power losses:

$$
\left\{\begin{array}{l}
E_{\mathrm{sDC}}^{\prime}=\sqrt{E_{\mathrm{sDC}}^{2}-\left(L_{\mathrm{DC}} \omega I_{\mathrm{sDC}}\right)^{2}} \\
I_{\mathrm{sDC}}^{\prime}=E_{\mathrm{sDC}}^{\prime} I_{\mathrm{sDC}} / E_{\mathrm{SDC}}
\end{array}\right.
$$

where $\omega$ is the electric angular pulsation associated with the rotor. The transient electric mode leads to a DC current in the generator defined as:

$L_{\mathrm{DC}} \frac{\mathrm{d} I_{\mathrm{SDC}}}{\mathrm{d} t}+R_{\mathrm{DC}} I_{\mathrm{SDC}}=E_{\mathrm{SDC}}^{\prime}-E_{\mathrm{DC}}$

Table 1

Correspondence between synchronous generator circuit and equivalent DC model.

\begin{tabular}{lll}
\hline Variable & Synchronous generator & Equivalent DC-model \\
\hline Voltage & $V_{\mathrm{S}}$ & $U_{\mathrm{DC}}=\frac{3 \sqrt{6}}{\pi} V_{\mathrm{S}}$ \\
Current & $I_{\mathrm{S}}$ & $I_{\mathrm{DC}}=\frac{\sqrt{6}}{\pi} I_{\mathrm{s}}$ \\
Flux & $\Phi_{\mathrm{S}}$ & $\Phi_{\mathrm{DC}}=\frac{3 \sqrt{6}}{\pi} \Phi_{\mathrm{S}}$ \\
Inductance & $L_{\mathrm{S}}$ & $L_{\mathrm{DC}}=3\left(\frac{\sqrt{6}}{\pi}\right)^{2} L_{\mathrm{S}}$ \\
Resistance & $R_{\mathrm{S}}$ & $R_{\mathrm{DC}}=3\left(\frac{\sqrt{6}}{\pi}\right)^{2} R_{\mathrm{S}}$ \\
Electromotive force & $E_{\mathrm{S}}$ & $E_{\mathrm{SDC}}=\frac{3 \sqrt{6}}{\pi} E_{\mathrm{S}}$ \\
\hline
\end{tabular}




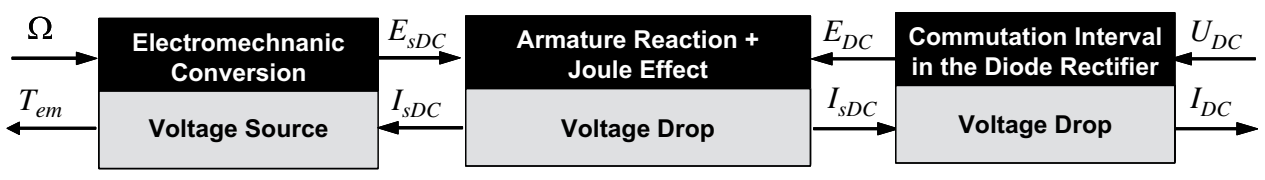

Fig. 9. The causal synoptic of the mixed-reduced model.

Table 2

The characteristics of the reference generator.

\begin{tabular}{ll}
\hline Design variables associated with the reference generator & Value \\
\hline Base power $P_{\mathrm{b}}$ & $600 \mathrm{~W}$ \\
Base speed $\Omega_{\mathrm{b}}$ & $16 \mathrm{rad} \mathrm{s}^{-1}$ \\
Base voltage $V_{\mathrm{b}}$ & $54 \mathrm{~V}$ \\
Number of pole pairs $p$ & 17 \\
Number of slots per pole per phase $\mathrm{N}_{\mathrm{spp}}$ & 1 \\
Radius/length ratio $R_{\mathrm{rl}}$ & 0.8 \\
Current density $J_{\mathrm{s}}$ & $1.9 \mathrm{~A} \mathrm{~mm}^{-2}$ \\
Yoke induction & $1.6 \mathrm{~T}$ \\
\hline
\end{tabular}

Finally, the diode overlapping during the commutation interval is represented by a power conservative voltage drop:

$\left\{\begin{array}{c}E_{\mathrm{DC}}=U_{\mathrm{DC}}+R_{\mathrm{emp}} I_{\mathrm{DC}} \\ I_{\mathrm{DC}}=E_{\mathrm{DC}} I_{\mathrm{SDC}} / U_{\mathrm{DC}}\end{array}\right.$

with

$R_{\mathrm{emp}}=\frac{3}{\pi} L_{\mathrm{s}} \omega$

\subsection{The mixed-reduced model}

When only the energetic system behavior is concerned, the electrical mode effect can be neglected and a further model reduction can be achieved. We have proposed the "mixed-reduced model" in which we only simulates the mechanical and thermal modes of the system, the whole electrical parts being analytically derived by merging the armature reaction with the Joule effect (see Fig. 9). This can be done by combining Eqs. (46) and (47) which gives:

$I_{\mathrm{sDC}}^{2}+\frac{2 U_{\mathrm{DC}}\left(R_{\mathrm{emp}}+R_{\mathrm{DC}}\right)}{\left(L_{\mathrm{DC}} \omega\right)^{2}+\left(R_{\mathrm{emp}}+R_{\mathrm{DC}}\right)^{2}} I_{\mathrm{SDC}}+\frac{U_{\mathrm{DC}}^{2}-E_{\mathrm{SDC}}^{2}}{\left(L_{\mathrm{DC}} \omega\right)^{2}+\left(R_{\mathrm{emp}}+R_{\mathrm{DC}}\right)^{2}}=0$

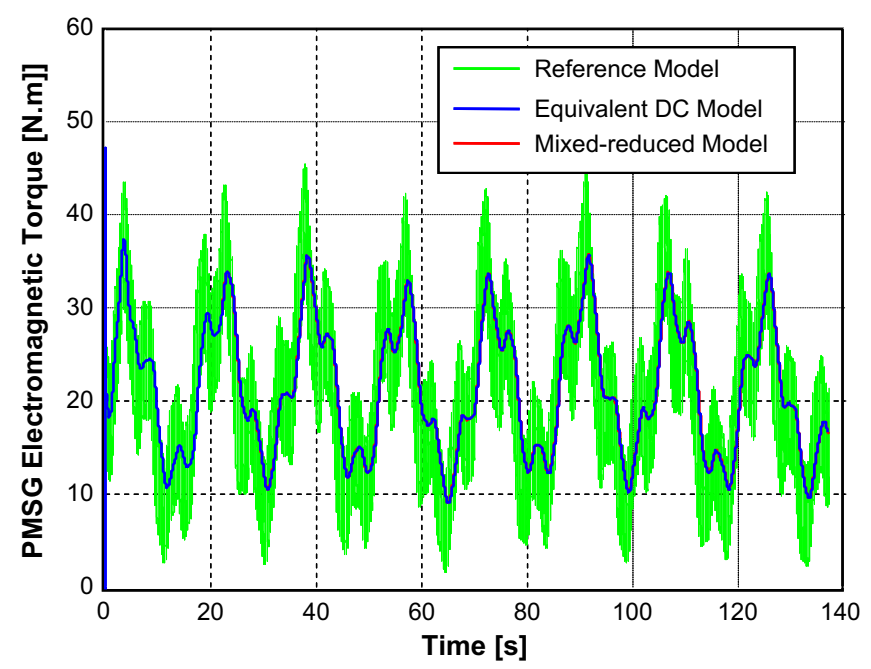

Fig. 10. Electromagnetic torque of the PMSG with the typical wind cycle considered.
DC current in the generator can be obtained by solving this equation.

\subsection{Validation and comparison of the wind turbine models}

To compare and validate the wind turbine models, we consider a "reference generator" similar to that used in our lab in earlier studies [15]. The design variables associated with this generator have been obtained from its electrical and geometrical features by inverting the sizing model of Section 3 (see Table 2).

The electromechanical behavior of the passive wind turbine system is evaluated with the different models considering the reference generator and the typical wind cycle [17], approximated by the following empiric relation:

$$
\begin{aligned}
V_{\mathrm{W}}(t)= & 10+0.2 \sin (0.105 t)+2 \sin (0.367 t)+\sin (1.293 t) \\
& +0.2 \sin (3.665 t)
\end{aligned}
$$

In particular the electromagnetic torque and the rotational speed of the generator, simulated with each model on this typical wind cycle, are displayed in Figs. 10 and 11. Although instantaneous values differ, it can be noted that differences are not significant and that average values are close for all models.

In Table 3 we also indicate the average values of the powers in each part of the system during the wind cycle (see Fig. 12). Iron and Joule losses in the PMSG are calculated from Eqs. (40) and (41). Conduction losses in the diode rectifier are computed according to Eq. (43). Mechanical losses in the turbine $P_{\text {mec }}$ are expressed as follows:

$P_{\text {mec }}=F_{\mathrm{WT}} \Omega^{2}$

It can be seen from Table 3 that the energetic behavior (i.e. powers and losses) of the wind turbine system is similar for all models. Note also that the system efficiency is not good without any MPPT control system, which justifies the passive wind turbine generator optimization.

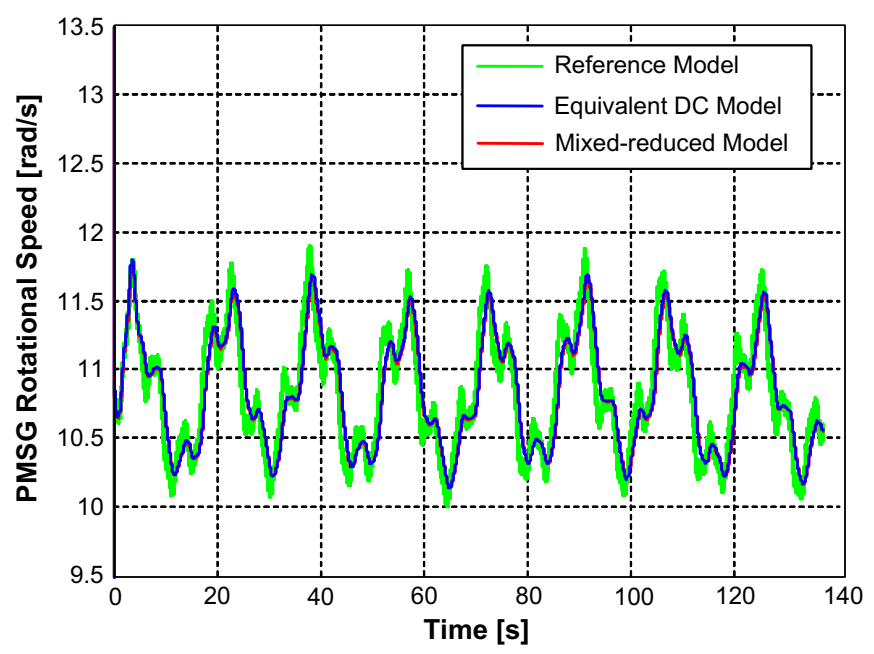

Fig. 11. Rotational speed of the PMSG with the typical wind cycle considered. 
Table 3

Average powers and losses in the passive wind turbine system during the wind cycle for all models of the wind turbine system.

\begin{tabular}{lccc}
\hline & $\begin{array}{c}\text { Reference } \\
\text { model }\end{array}$ & $\begin{array}{c}\text { Equivalent } \\
\text { DC model }\end{array}$ & $\begin{array}{l}\text { Mixed-reduced } \\
\text { model }\end{array}$ \\
\hline Wind turbine power $P_{\mathrm{WT}}[\mathrm{W}]$ & 241.0 & 240.9 & 240.6 \\
Mechanical losses $P_{\text {mec }}[\mathrm{W}]$ & 7.0 & 7.0 & 7.0 \\
PSMG power $P_{\mathrm{em}}[\mathrm{W}]$ & 234.3 & 233.8 & 233.6 \\
Iron losses $P_{\text {iron }}[\mathrm{W}]$ & 41.1 & 44.0 & 43.9 \\
Joule losses $P_{\mathrm{j}}[\mathrm{W}]$ & 23.8 & 20.4 & 20.3 \\
Conduction losses $P_{\text {cond }}[\mathrm{W}]$ & 6.2 & 6.2 & 6.5 \\
Useful power $P_{\mathrm{u}}[\mathrm{W}]$ & 163.3 & 163.2 & 163.0 \\
\hline
\end{tabular}

Table 4 summarizes the step size used for all models in the ODEs and the corresponding CPU time required for simulating the wind cycle (i.e. 2 min of wind) on a standard PC computer. The CPU time of the most accurate model (i.e. the reference model) is really too high to simulate wind cycles with high durations or in an optimization context where the wind cycle has to be simulated many times. The best CPU time, obtained with the mixed-reduced model, is about 7000 times lower than that of the reference model! With an equivalent accuracy, this demonstrates the interest of the model simplification approach developed in the previous section.

\section{Multiobjective optimization of the passive wind turbine}

In this section, the optimization of the passive wind turbine system is carried out using a multiobjective genetic algorithm.

\subsection{Design variables, constraints and objectives}

The design variables considered for the wind turbine optimization and their associated bounds are shown in Table 5 . Six variables are continuous (i.e. $R_{\mathrm{rl}}, P_{\mathrm{b}}, \Omega_{\mathrm{b}}, V_{\mathrm{b}}, B_{\mathrm{y}}$, and $J_{\mathrm{s}}$ ) and two are discrete (i.e. $p$ and $N_{\text {spp }}$ ). Two conflicting objectives have to be improved with respect to these variables: the useful power has to be maximized while minimizing the total embedded mass of the system.

When varying the design variables in their corresponding range, five constraints have to be fulfilled to ensure the system feasibility. The first two constraints $\left(g_{1}\right.$ and $\left.g_{2}\right)$ concern the number $N_{\mathrm{cs}}$ of copper windings per slot. This number has to be higher than one and bounded by the slot section in relation to the minimum winding section $S_{\text {winding }}$ (this last is set to $0.5 \mathrm{~mm}^{2}$ ).

$g_{1}=1-N_{\mathrm{cs}} \leq 0$

$g_{2}=S_{\text {winding }}-\frac{d_{\mathrm{S}} w_{\mathrm{S}} K_{\mathrm{r}}}{N_{\mathrm{CS}}} \leq 0$

The third constraint $\left(g_{3}\right)$ prevents magnet demagnetization:

$g_{3}=\widehat{B}_{\mathrm{S}}-\widehat{B}_{\mathrm{g}}-B_{\mathrm{D}} \leq 0$
Table 4

Step size used in ODEs and corresponding CPU time required to simulate the wind cycle for all models of the wind turbine system.

\begin{tabular}{llll}
\hline & $\begin{array}{l}\text { Reference } \\
\text { model }\end{array}$ & $\begin{array}{l}\text { Equivalent } \\
\text { DC model }\end{array}$ & $\begin{array}{l}\text { Mixed-reduced } \\
\text { model }\end{array}$ \\
\hline Step size in ODEs [ms] & 0.05 & 1.35 & 100 \\
CPU time [s] & 660 & 9.8 & 0.1 \\
\hline
\end{tabular}

where the magnet demagnetization induction limit $B_{\mathrm{D}}$ is $-0.2 \mathrm{~T}$ and the stator induction is defined as follows:

$\widehat{B}_{\mathrm{S}}=\frac{3 \mu_{0} N_{\mathrm{spp}} N_{\mathrm{cs}} I_{\mathrm{S}}}{K_{\mathrm{c}} g+l_{\mathrm{m}} / \mu_{\mathrm{r}}}$

An additional constraint $\left(g_{4}\right)$ verifies that the temperature of the copper windings $\left(T_{\text {copper }}\right)$ does not exceed the critical limit of insulators (typically $T_{\text {copper_max }}=160^{\circ} \mathrm{C}$ or $433 \mathrm{~K}$ ) during a wind cycle:

$g_{4}=T_{\text {copper }}-T_{\text {copper_max }} \leq 0$

where $T_{\text {copper }}$ is evaluated according to the thermal model described in Section 3.3.

Finally, the last constraint $\left(g_{5}\right)$ ensures that the temperature on the semiconductor junctions in the diode rectifier stays below the technological limit (typically $\mathrm{T}_{\mathrm{j} \_\max }=125^{\circ} \mathrm{C}$, i.e. $398 \mathrm{~K}$ ) during a wind cycle:

$g_{5}=T_{\mathrm{j}}-T_{\mathrm{j} \_ \text {max }} \leq 0$

where the temperature on the semiconductor junction is calculated according to the thermal model of Fig. 6, from the conduction losses during the wind cycle.

It can be noted that the first two constraints are evaluated before simulating the wind cycle. If one of these constraints is not fulfilled, the next constraints take the maximum penalty value (i.e. $g_{3,4,5} \rightarrow \infty$ "death penalty"). On the other hand, if the first two constraints are fulfilled, the wind turbine system is simulated and the next constraints are evaluated during the wind cycle. Thus, three "cumulative" constraints $G_{1,2,3}$ associated with $g_{1,2,3}$ are defined as follows:

$G_{3,4,5}=\sum_{k} \max \left(0, g_{3,4,5}(k)\right)$

where $k$ denotes the set of points defining the wind cycle.

\subsection{The optimization process}

The non-dominated sorting genetic algorithm (NSGA-II) [24] is applied for the optimization of the "full passive" wind turbine generator. The NSGA-II is coupled with the sizing and simulating models presented in the previous sections. The most accurate model, which can be used in an optimization process where multiple simulations are performed, is employed for simulating the

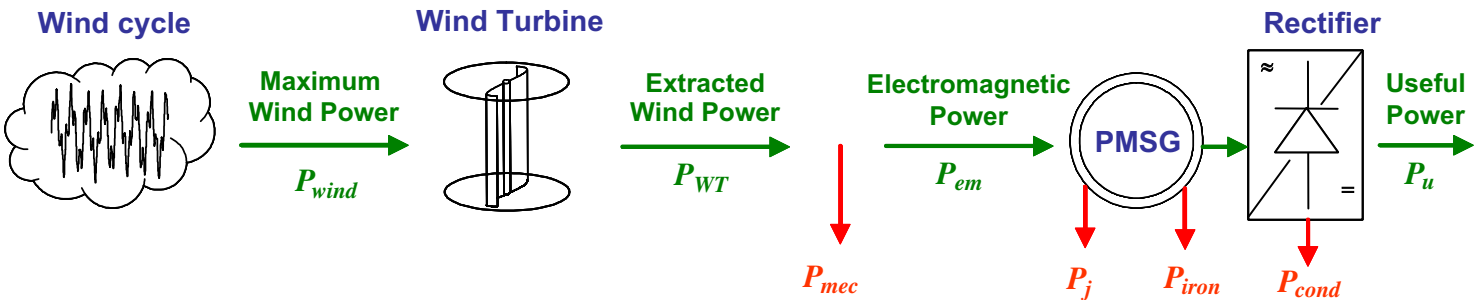

Fig. 12. Power assessment in the passive wind system. 
Table 5

Design variable bounds.

\begin{tabular}{|c|c|c|}
\hline Design variable & Nature & Bounds \\
\hline$\overline{\text { Base voltage [V] }}$ & Continuous & $V_{\mathrm{b}} \in[1,200]$ \\
\hline Radius/length ratio & Continuous & $R_{\mathrm{rl}} \in[0.1,10]$ \\
\hline Number of pole pairs & Discrete & $p \in\{1, \ldots, 60\}$ \\
\hline Current density $\left[\mathrm{A} \mathrm{mm}^{-2}\right]$ & Continuous & $J_{s} \in[0.5,10]$ \\
\hline Base power [W] & Continuous & $P_{\mathrm{b}} \in[1,700]$ \\
\hline Base speed [ $\mathrm{rad} \mathrm{s}^{-1}$ ] & Continuous & $\Omega_{\mathrm{b}} \in[3,32]$ \\
\hline Yoke induction [T] & Continuous & $B_{\mathrm{y}} \in[1.2,1.9]$ \\
\hline Number of slots per pole per phase & Discrete & $N_{\mathrm{spp}} \in\{1, \ldots, 6\}$ \\
\hline
\end{tabular}

wind turbine behavior. We choose the equivalent DC model since its CPU time is still acceptable for a large number of simulations. For each candidate solution investigated by the multiobjective genetic algorithm, objectives and constraints are evaluated considering the wind cycle defined in Section 5.4.

Note that other wind cycles synthesized from wind statistics have also been used for this optimisation process as presented in [26].

To take into account the design constraints in the NSGA-II, the Pareto-dominance rule is modified as follows:

- if two individuals are non-feasible, the Pareto-dominance relative to these individuals is applied in the constraint space.
Table 6

Design variables of the four particular solutions of Fig. 13b.

\begin{tabular}{lcccc}
\hline Design variable & Solution 1 & Solution 2 & Solution 3 & Solution 4 \\
\hline$B_{\mathrm{y}}(\mathrm{T})$ & 1.9 & 1.9 & 1.2 & 1.2 \\
$J_{\mathrm{s}}\left(\mathrm{A} / \mathrm{mm}^{2}\right)$ & 5.0 & 5.0 & 3.2 & 2.3 \\
$N_{\mathrm{epp}}$ & 5 & 5 & 5 & 5 \\
$p$ & 7 & 5 & 3 & 2 \\
$P_{\mathrm{b}}(\mathrm{W})$ & 525.8 & 557.0 & 674.7 & 747.4 \\
$R_{\mathrm{rl}}$ & 1.05 & 0.81 & 0.64 & 0.68 \\
$V_{\mathrm{b}}(\mathrm{V})$ & 75.8 & 76.8 & 100.6 & 118.6 \\
$\Omega_{\mathrm{b}}(\mathrm{rad} / \mathrm{s})$ & 18.0 & 17.6 & 17.0 & 16.7 \\
\hline
\end{tabular}

- if two individuals are feasible, the Pareto-dominance relative to these individuals is applied in the objective space.

- if one individual is feasible and the other is non-feasible, the feasible individual dominates the non-feasible individual.

In this manner, Pareto ranking tournaments between individuals include the constraint as well as the objective minimization. Note that in the case of the NSGA-II, for non-feasible individuals belonging to a given front in the constraint space, the computation of the I-distance density estimator is carried out in relation to all constraints [19]. In this way, niching will occur in the two different spaces (i.e. constraint and objective spaces) and diversity will be preserved to avoid premature convergence.

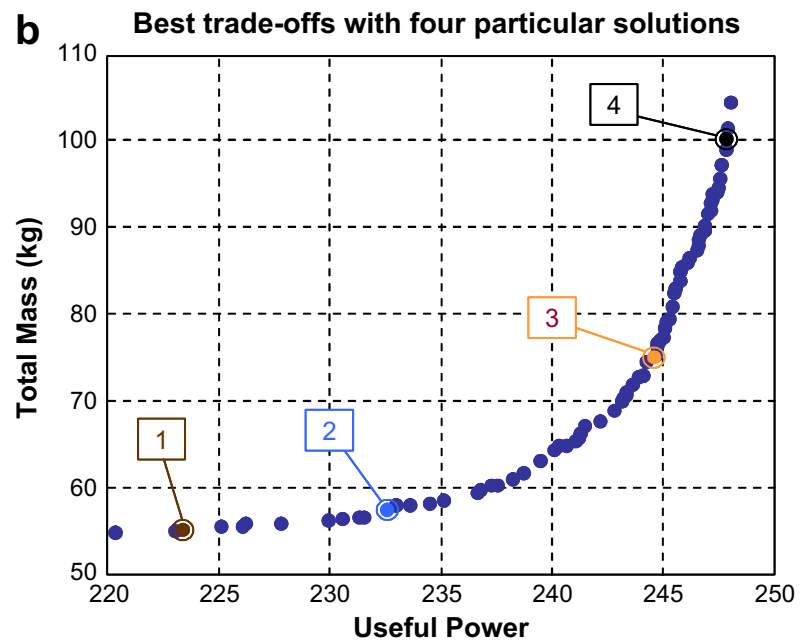

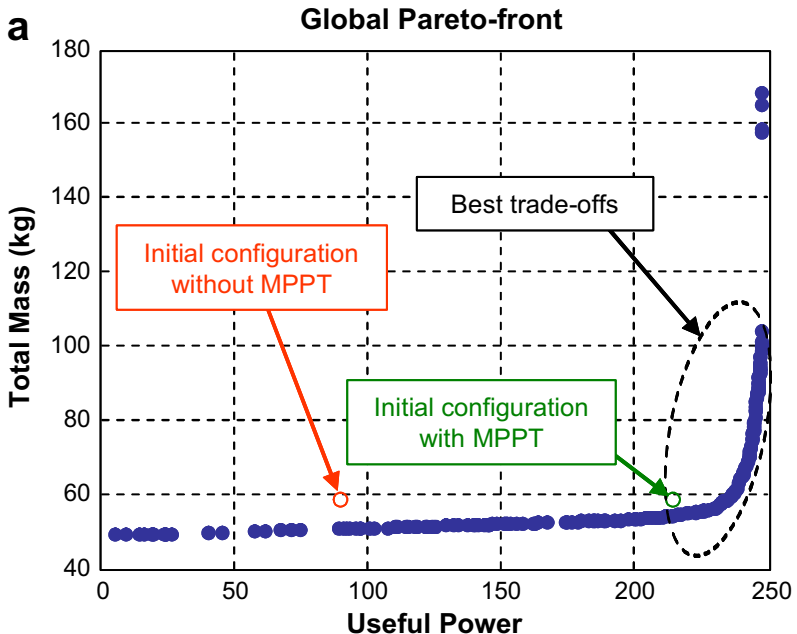

C Extracted Power of the four particular solutions

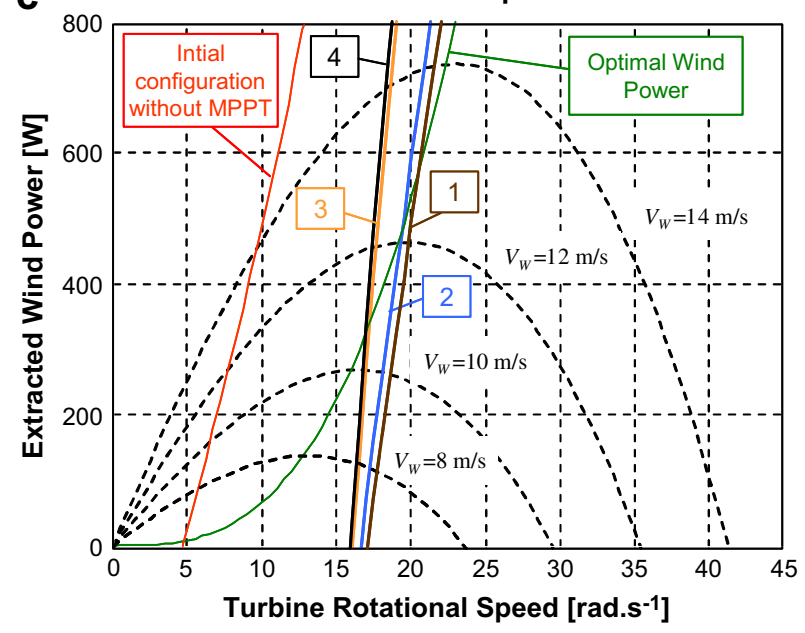

Fig. 13. Pareto-optimal configurations of the passive wind turbine system. 
Table 7

Average powers and losses of four passive optimized wind turbine solutions compared with the initial configuration used with or without a MPPT device.

\begin{tabular}{|c|c|c|c|c|c|c|}
\hline $\begin{array}{l}\text { System } \\
\text { power } \\
\text { and losses }\end{array}$ & $\begin{array}{l}\text { Initial } \\
\text { configuration } \\
\text { without MPPT }\end{array}$ & $\begin{array}{l}\text { Initial } \\
\text { configuration } \\
\text { with MPPT }\end{array}$ & 1 & 2 & 3 & 4 \\
\hline$\overline{P_{\mathrm{WT}}[\mathrm{W}]}$ & 136.9 & 284.6 & 281.1 & 282.3 & 282.1 & 281.5 \\
\hline$P_{\text {mec }}[\mathrm{W}]$ & 1.6 & 16.3 & 18.9 & 17.9 & 16.2 & 15.3 \\
\hline$P_{\mathrm{em}}[\mathrm{W}]$ & 135.3 & 268.3 & 262.2 & 264.4 & 265.9 & 266.2 \\
\hline$P_{\text {iron }}[\mathrm{W}]$ & 9.9 & 37.3 & 21.8 & 13.7 & 10.3 & 9.1 \\
\hline$P_{\mathrm{j}}[\mathrm{W}]$ & 28.5 & 11.6 & 13.4 & 14.5 & 8.6 & 6.8 \\
\hline$P_{\text {cond }}[\mathrm{W}]$ & 7.6 & 4.6 & 3.4 & 3.3 & 2.6 & 2.2 \\
\hline$P_{\mathrm{u}}[\mathrm{W}]$ & 89.3 & 214.8 & 223.6 & 232.9 & 244.4 & 248.1 \\
\hline
\end{tabular}

Five independent runs are performed to take into account the stochastic nature of the NSGA-II. The population size and the number of non-dominated individuals in the archive are set to 100 and the number of generations is $G=200$. Mutation and recombination operators are similar to those presented in [25]. They are used with a crossover probability of 1 , a mutation rate on design variables of $1 / \mathrm{m}$ ( $m$ is the total number of design variables in the problem) and a mutation probability of $5 \%$ for the $X$-gene parameter used in the self-adaptive recombination scheme.

\subsection{The optimization results}

The best trade-offs determined from the five independent runs are displayed in Fig. 13. The global Pareto-optimal front is obtained by merging all fronts associated with these runs. The characteristics of four typical solutions of the Pareto-front and of the "reference" system (the corresponding design variables of these solutions are mentioned in Table 6) are represented in this figure. It should be noted that the "reference" generator is able to operate at optimal wind powers when it is associated with a MPPT control device but presents a "poor" efficiency if the MPPT is suppressed. As shown in Fig. 13(a), the useful power is strongly reduced in this case. The wind turbine optimization considerably improves both objectives. As can be seen in Fig. 13(c), these passive optimized solutions can match very closely the behavior of active wind turbine systems operating at optimal wind powers by using a MPPT control device. Some Paretooptimal solutions are slightly better than the initial configuration of the generator with a MPPT control device which still presents the best wind power extraction (see Table 7). However, it can be seen from this table that losses in the system are considerably reduced through the global optimization process, which explains the good efficiency of passive wind turbine configurations.

\subsection{The model sensitivity analysis}

- Comparison with the reference model

To analyse the model sensitivity related to optimization results, we simulate the Pareto-optimal configurations obtained in the previous section with the reference model. In this case, the values of the PMSG inductances used in the reference model are those obtained with the Finite Element Method (FEM) [17]. It can be seen from Fig. 14 that the differences between the most accurate wind turbine model (FEM sizing + reference model simulation) and the equivalent DC model with analytical sizing are rather small.

- Comparison with the mixed-reduced model

The same approach was applied to optimize passive wind turbine configurations using the previous optimization process and the mixed-reduced model (instead of the equivalent DC model). Five NSGA-II runs were performed with the control parameters of Section 6.2. The results obtained with the mixedreduced and the equivalent DC models were quite identical. Thus, the fastest simulating model (i.e. the Mixed-reduced model) can be used for optimizing passive wind turbine systems in relation to wind cycles with higher durations [26] (more than 200 min of wind) without loosing accuracy.

\section{Conclusions}

In this paper, a "low cost full passive structure" of a wind turbine system has been proposed. It has been put forward that an efficient operation of such a device can be obtained only if the design parameters are conveniently and mutually set from a system viewpoint. For that purpose, several sizing and simulating models of the passive wind turbine system have been developed. The simplified model approach leads to a large reduction of computational time which allows the investigation of multiple system configurations through a multiobjective optimization process. In particular, the energetic efficiency has been maximized while the total embedded mass have been minimized, leading to Pareto-optimal
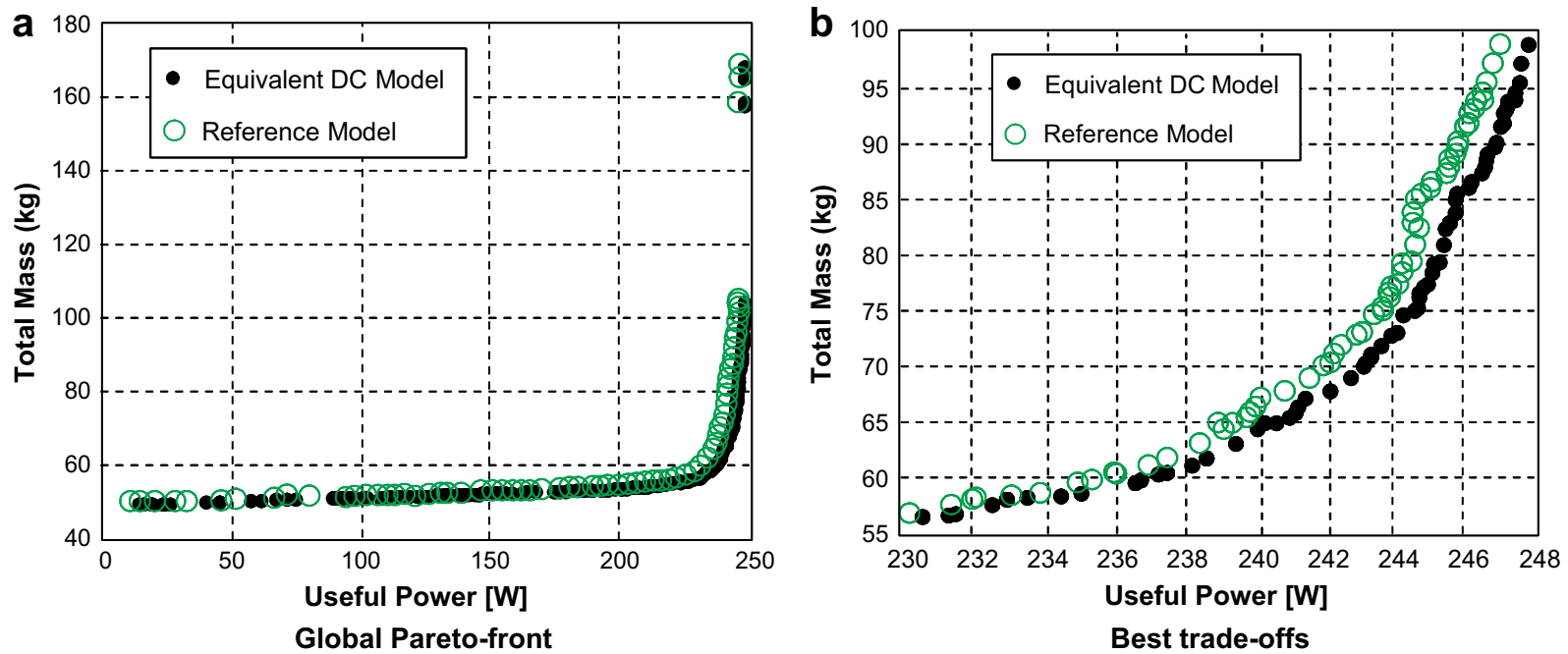

Fig. 14. Differences between the reference model and the equivalent DC model for Pareto-optimal configurations. 
solutions. The results show that the optimized configurations of the passive wind turbine generators are able to match very closely the behavior of active wind turbine systems which operate at optimal wind powers by using a MPPT control device.

\section{References}

[1] Baroudi JA, Dinavahi V, Knight AM. A review of power converter topologies fo wind generators. Renewable Energy 2007;32:2369-85.

[2] Prats MAM, Carrasco JM, Galvan E Sanchez JA, Franquelo LG, Batista C. Improving transition between power optimization and power limitation of variable speed, variable pitch wind turbines using fuzzy control techniques. In: Twenty-sixth annual conference of the IEEE industrial electronics society, vol. 3. IECON2000; 2000. 1497-1502.

[3] Anandavel P, Rajambal K, Chellamuthu C. Power optimization in a grid-connected wind energy conversion system. IEEE International Conference on Power Electronic and Drives Systems 2005;2:1617-721.

[4] Sourkounis C, Ni B. Optimal control structure to reduce the cumulative load in the drive train of wind energy converters. In: Eleventh European conference on power electronics and applications. Dresden: EPE2005; 2005.

[5] Sourkounis C, Ni B. Iterative adapting power control for wind energy converters based on stochastic optimization. In: Ninth international conference on probabilistic methods applied to power systems. Stockholm, Sweden: KTH; June 11-15, 2006.

[6] Neris AS, Vovos NA, Giannakopoulos GB. A variable wind energy conversion scheme for connection to weak AC systems. IEEE Transactions on Energy Conversion 1999;14(1)

[7] De Broe AM, Drouilhet S, Gevorgian V. A peak power tracker for small wind turbines in battery charging applications. IEEE Transactions on Energy Conversion 1999;14(4):1630-5.

[8] Yang JM, Wu J, Dong P, Yang JH. Passivity-based control in wind turbine for maximal energy capture. In: IEEE international conference on electric utility deregulation, restructuring and power technologies. Hong Kong: DRPT2004; April 2004.

[9] E. Muljadi, S. Drouilhet, R. Holz, V. Gevorgian, Analysis of wind power for battery charging, in: Proceedings of the 1996 Fifteenth ASME Wind Energy Symposium, 1996.

[10] S. Drouilhet, E. Muljadi, R. Holz, V. Gevorgian, Optimizing small wind turbine performance in battery charging applications, in: 25th annual conference and exhibition on wind power, Washington, DC (United States), 1995.

[11] Shi KL, Li H. A novel control of a small wind turbine driven generator based on neural networks. IEEE Power Society General Meeting 2004:2:1999-2005.
[12] Chen Z, Gomez S, Mc Cormic M. A fuzzy logic controlled power electronic system for variable speed wind energy conversion systems. In: Proceedings of power electronic \& variable speed drives. IEE Publication; 2000. p. 114-9. No. 475.

[13] Stannard N, Bumby JR. Performance aspects of mains connected small scale wind turbines. IET Generation, Transmission \& Distribution (Formerly IEE Proceedings) March 2007;1(2):348-56.

[14] Bouscayrol A, Delarue Ph, Guillaud X. Power strategies for maximum control structure of a wind energy conversion system with a synchronous machine. Renewable Energy 2005;30(15):2273-88.

[15] Mirecki A, Roboam X, Richardeau F. Architecture cost and energy efficiency of small wind turbines: which system tradeoff? IEEE Transactions on Industrial Electronics February 2007;54(1):660-70.

[16] O. Gergaud, B. Multon, H. Ben Ahmed, Modélisation d'une chaîne de conversion éolienne de petite puissance, Proceedings d'Electrotechnique du Futur 2001, Nancy, Nov 2001, pp. 17-22.

[17] Abdelli A Sareni B, Roboam X. Optimization of a small passive wind turbine generator with multiobjective genetic algorithms. IJAEM (Intern Journal of Applied Electromagnetics) 2007;26(3-4):175-82 (selected from OIPE’06 conference).

[18] A. Abdelli, Optimisation multicritère d'une chaîne éolienne passive, Thèse de doctorat (PHD) de l'INP Toulouse, 15 Octobre 2007.

[19] Sareni B, Regnier J, Roboam X. Integrated optimal design of heterogeneous electrical energetic systems using multiobjective genetic algorithms. IREE (International Review of Electrical Engineering) 2006;1(1):112-29. 1827-6600.

[20] Hau E. In: Wind turbines: fundamentals, technologies, application, economics. 2nd ed. Springer-Verlag; 2006.

[21] Slemon G, Liu X. Modeling and design optimization of permanent magnet motors. Electrical Machines and Power Systems 1992;20:71-92.

22] F. Chabot, Lajoie-Masenc, Analytical model of the design of permanent magnet machines, SPEEDAM 98, Symposium on Power Electronics, Electrical Drives, Advanced Machines, Sorrento, Italy, June 1998.

[23] Hoang E, Multon B, Gabsi M. Enhanced accuracy method for magnetic loss measurement in switched reluctance motor. ICEM'94 1994;2:437-42.

[24] K. Deb, S. Agrawal, A. Pratab, T. Meyarivan, A fast-elitist non-dominated sorting genetic algorithm for multiobjective optimization: NSGA-II, in: Proceedings of the Parallel Problem Solving from Nature VI Conference, Athens, Greece, 2000, pp. 849-858.

[25] Sareni B, Regnier J, Roboam X. Recombination and self-adaptation in multiobjective genetic algorithms. In: Lecture notes in computer science, vol. 2936; 2004. 115-126.

[26] X. Roboam, A. Abdelli, B. Sareni, Optimization of a passive small wind turbine based on mixed Weibull-turbulence statistics of wind, Electrimacs Conference, Québec, Canada, June 2008. 